\title{
The Doomed Race: A Scientific Axiom of the Late Nineteenth Century
}

Russell McGregor

Anthropologists and other scientific investigators of the Australian Aborigines in the late nineteenth and early twentieth centuries confidently predicted the imminent extinction of the race. Indeed, "confidently predicted" is understating the case. Scientists at the time knew that the Aborigines would soon be extinct. It was taken for granted as a self-evident truth. James Barnard, Vice-President of the Royal Society of Tasmania, opened his paper at the $\mathbf{1 8 9 0}$ meeting of the Australasian Association for the Advancement of Science with the assertion:

It has become an axiom that, following the law of evolution and survival of the fittest, the inferior races of mankind must give place to the highest type of man, and that this law is adequate to account for the gradual decline in numbers of the aboriginal inhabitants of a country before the march of civilisation. ${ }^{2}$

This paper seeks to explain why the inevitable extinction of the Aborigines was raised to the status of an axiom. It will discuss both the supportive empirical evidence and the presuppositions which underlay contemporary scientific understandings of the Aborigines. The latter of these was by far the most important.

By the late nineteenth century the prediction of Aboriginal extinction was by no means novel. It had been put forward by Barron Field and others early in the century and repeated by numerous observers over subsequent decades. ${ }^{3}$ What was new was the explanatory framework: the Natural Law of Survival of the Fittest replaced Divine Providence as its intellectual foundation. In a sense, this was little more than a dressingup in the newly-fashionable language of evolutionary theory. Nonetheless, the fashionable dress did lend the respectability and certainty of science.

According to the evolutionists, Aborigines ranked as one of the most primitive of human races: living fossils which had survived, through seclusion, in this remote part of the world. Since Europeans first encountered them, Aborigines had been regarded as a particularly low and inferior variety of humanity. ${ }^{4}$ The racial scientists of the late eighteenth and early nineteenth centuries had consistently placed them on the bottom of the racial hierarchy, along with Tierra del Fuegians and the Hottentots of Africa. ${ }^{5}$ The advent of evolutionary interpretations of humanity in the latter half of the nineteenth century did nothing to alter the Aborigines' placement on the racial hierarchy. It merely changed their reason for being there. No longer did their lowly status signify their ordained place in Creation. It now signified their retarded stage of advancement along an evolutionary sequence.

It was their assumed primitivity which lent Aborigines their unique value to science. The physical anthropologist Dr W. Ramsay Smith asserted that: 
Centuries ago, nature 'side tracked' a race in Australia. At the present time, despite some drawbacks or interference from outside, that race remains, to a large extent in primitive conditions. It is capable of casting light on the evolution of human races in a way and to an extent that probably no other can equal. ${ }^{6}$

Not only its human inhabitants, but the entire flora and fauna of Australia was thought to have fossilised at a primitive stage. Baldwin Spencer, Australia's most eminent evolutionary anthropologist, who was also Professor of Biology at Melboume University, expressed this idea perfectly in the first paragraph of the preface to his book, The Arunta:

Australia is the present home and refuge of creatures, often crude and quaint, that have elsewhere passed away and given place to higher forms. This applies equally to the aboriginal as to the platypus and kangaroo. Just as the platypus, laying its eggs and feebly suckling its young, reveals a mammal in the making, so does the aboriginal show us, at least in broad outline, what early man must have been like before he learned to read and write, domesticate animals, cultivate crops and use a metal tool. It has been possible to study in Australia human beings that still remain on the culture level of men of the Stone Age. ${ }^{7}$

To the evolutionary scientist of the late nineteenth century, Australia was a huge museum of antiquated forms of life.

The belief that they had to hand the "living reality" of Stone Age Man inspired and informed numerous Australian anthropologists in the late nineteenth and early twentieth centuries. Study of the Aborigines could provide details about an antiquity well beyond the earliest historical records. A. W. Howitt was convinced that "in Australia, if anywhere, one might expect to find primitive institutions preserved". 8 He devoted his efforts to unravelling Aboriginal kinship systems and marriage customs, which, he believed, represented an early step in the evolution of the family toward its highest form, monogamy. ${ }^{9}$ Baldwin Spencer and F. J. Gillen paid particular attention to Aboriginal "superstitions" and ceremonies, which they considered to be the primitive precursors of religion. ${ }^{10}$ While Aboriginal society, customs and beliefs were a major focus of investigation in Australia, the other important areas of anthropological concern physical characteristics, material culture, intellectual status - were not neglected. According to the tenets of contemporary science, all aspects of a human group evolved more or less together, so that a race possessing, for example, primitive customs could be expected to display also archaic physical traits, an undeveloped intellect, a low technology and other attributes of primitivity. Indeed, for the late nineteenth century scientist one of the most appealing features of evolutionary theory lay in its capacity to encompass the entire range of human attributes in a single bio-social law. ${ }^{11}$

Darwin's friend T. H. Huxley was the first to draw attention to a similarity between Aboriginal skulls and fossil crania such as that from Neanderthal. ${ }^{12}$ With the growth of the sciences of craniology and craniometry in the late nineteenth century, numerous physical anthropologists subjected Aboriginal skulls to meticulous examination and minute measurement. All found archaic traits and a low cranial capacity. The former was supposed to indicate the Aborigines' lack of development; the latter their lack of intellect. According to one prevalent theory, early closure of the cranial sutures in the black races caused premature cessation of growth of the brain and thus of the intellect. To this theory, Dr Alan Carroll, President of the Australasian Anthropological Association, added that in the Aborigine "the brain material already there" was prevented from "developing into higher forms of organisation". ${ }^{13}$ It was commonly asserted that the Aboriginal mind was "child-like", by which was meant, quite literally, that Aboriginal mental development was arrested at a stage reached by Europeans in childhood. ${ }^{14}$ Evidence from both physical and social anthropology was adduced to demonstrate the inferiority and primitivity of Aboriginal mentality. Even those qualities in which Aborigines apparently excelled 
Europeans - for example tracking and bushcraft - could be used as evidence of their primitivity. ${ }^{15}$ For these were regarded as the products merely of instinct or of acute sensory perception: all animal-like qualities which the European, in his upward course toward civilisation, had outgrown.

Particularly in the work of the physical anthropologists, Aboriginal traits were correlated not merely with those of primitive humanity but with those of their simian ancestors. Dr Ramsay Smith proudly declared that "almost every part of the anatomy of the aboriginal is being examined and re-examined with the view of discovering keys that will open up the secrets of human origins". ${ }^{16}$ Dr Smith paid particular attention to Aboriginal dentition, finding rudiments of the dental arrangement of apes. ${ }^{17}$ Dr Alan Carroll argued that certain distinctive features of the vertebral bones of Australians and Tasmanians, which were also found in gorillas and chimpanzees, revealed their "approach to the brutal type". ${ }^{18}$ Dr Carroll also claimed that Aborigines possessed a prehensile toe which they used to climb trees and to grasp spears and other objects. ${ }^{19} \mathrm{~A}$ visiting German ethnologist, Otto Schoetensack, asserted that "the primitive character of the Australian is proved by certain features of their sexual habits", in particular, "the concentration of their sexual intercourse upon a particular part of the year, which is a remnant from their animal stage of development". 20 Summing up the results of decades of research into physical anthropology, Dr Ramsay Smith declared that "the Australian aboriginals have furnished the largest number of ape-like characters. The more one investigates, the truer does this statement prove to be".21

Dr Ramsay Smith's remark was a revealing one. For scientists did indeed investigate Aborigines on the presumption that their studies would uncover "ape-like" or primitive characteristics. In turn, their findings served to reinforce the already existing scientific image of the Aborigine as the archetypal primitive man. Locked into an evolutionary paradigm, anthropology did not seek to investigate whether Aborigines were primeval forms of humanity. That was already known. Rather it sought to discover from Aborigines what the primeval forms of human society, customs, beliefs, mentality and physique really were. Information about Aborigines, which was assumed to be equally information about primordial man, could be incorporated into more elaborate theories tracing the evolutionary development of mankind. By the late nineteenth century, data from the antipodes was an essential ingredient of virtually every European theory of the course of human evolution. Australia provided one of the foundation stones for coherent and intellectually satisfying theoretical edifices explaining, in terms of a natural law, the apparently awesome progress of man from ape to Anglo-Saxon.

Aboriginal extinction was a corollary of their primitivity. A people so undeveloped and immature could not possibly survive in competition with the superior and progressive European races, any more than the dinosaur could survive into the age of mammals. A race which had stagnated for untold ages in an evolutionary backwater now had the modern world thrust suddenly upon it. W. L. Cleland, President of the Royal Society of South Australia, expressed the matter tersely:

no longer protected by isolation [the Aborigine] must shortly entirely disappear from the face of the earth, for he is an anachronism and archaic. 22

In the context of late nineteenth century science, the argument was coherent and convincing.

While the doomed race concept had firm theoretical foundations in contemporary science, its empirical supports were remarkably tenuous. No accurate demographic data was available and no detailed demographic studies were conducted. Colonial censuses sometimes ignored, sometimes estimated the Aboriginal population; at times those in 
settled districts or those working for Europeans were enumerated; on other occasions they were not. ${ }^{23}$ This, combined with changing definitions of who was to be included in the category "Aboriginal" made the census data totally inadequate - even irrelevant - as a guide to population trends. Moreover, what census data was available did not unequivocally indicate a race plummeting toward extinction. For example, the Queensland census of 1881 suggested an Aboriginal population for the colony of 70,000, admitting that this was "a very crude estimate." Five years later the Aboriginal population was estimated at a mere 20,000; and in 1901 the figure was revised upward to $26,670.24$ The only definite conclusion that could be reached from these sorts of figures was that a lot of guesswork was involved. Non-official estimates were no better. In 1912 Baldwin Spencer claimed the Aboriginal population of the Northern Territory to be "more nearly 50,000 " than the previously accepted figure of 20,000 . He was nonetheless convinced that they were "dying out with great rapidity". ${ }^{25}$

Of course, the collection of detailed population statistics would have been a daunting and difficult task, and the analysis of population trends the labour of many years. No one even attempted to do so. One might expect the lack of such vital statistics at least to counsel some caution in prediction. Yet caution was precisely what was lacking in the bold and confident assertion of imminent racial extinction.

Certainly there were observations which lent credence to the doomed race idea. There was the example of Tasmania where, taking contemporary definitions of race for granted, the indigenous inhabitants had become extinct. ${ }^{26}$ However, it was one thing to suggest that what had happened in Tasmania could, possibly, occur on the mainland; it was quite another to assert that it positively would.

Virtually the only available information on the Aboriginal population was anecdotal: a collection of casual and unsystematic observations. These could normally be reduced to the formulae: "there used to be lots of blackfellows around here and now there aren't many" or "there's King Billy, the last of his tribe". Such observations may have plausibly suggested population decline. But from that to inevitable extinction required a long imaginative leap, with no detailed empirical evidence to bridge the gap.

While scientists could pronounce confidently on the reasons for racial extinction at a theoretical level, on the causes of actual Aboriginal deaths they wrote with far less selfassurance. Charles Darwin devoted a section of The Descent of Man to the "Extinction of the Races of Man". (He believed that the Australians were high on the list.) After discussing the impact of introduced diseases and of alcohol, the supposed inability of "savages" to change their habits and their lack of motivation, he was forced to conclude that "the gradual decrease and final extinction of the races of man is an obscure problem". ${ }^{27}$ Later explanations by his followers were no better, and a good deal less candid. Very little research, none of it systematic, addressed the problem of how the Aborigines would all die out - the physical causes of death. Scientific treatment of this vital, if mundane, aspect of the doomed race prediction was at best perfunctory, at worst vague and confused. So much was Aboriginal extinction taken for granted that this inadequacy was apparently of small consequence.

Insofar as any attempt was made to explain the physical process of dying out, Australian anthropologists basically followed Darwin, citing disease, drink, drugs and the demoralisation which followed the "vices of civilisation". Plausible as these may have been as causes of population decline, they fell far short of explaining total extinction; the more so as scientists were unable to explain how or why such factors should be so devastating. Some suggested an inherent racial trait which made Aborigines peculiarly susceptible. ${ }^{28}$ But an unspecified and unknown "racial peculiarity" does not mark much of an advance over Darwin's "obscure problem". 
In a confused way, disease and degradation were treated as simultaneously cause and symptom of the Aboriginal demise. To add to the confusion, the deleterious influences of disease, drugs and demoralisation were frequently attributed to Chinese and other "Asiatic aliens", while in other contexts the same scientists would attribute racial extinction to the struggle with the superior white race. Howitt claimed that the "rapid extinction" of the Queensland blacks was due in large measure to opium abuse. ${ }^{30} \mathrm{~A}$ visiting German anthropologist, Hermann Klaatsch, remarked on the "state of decay" of the Aborigines in North Queensland "owing to the introduction of opium by the Chinese". ${ }^{31}$ Carl Lumholtz illustrated his remark about the "degeneration and demoralisation of the natives, which are an inevitable result of the march of civilisation" with a vivid description of a group of Aboriginal opium addicts from the Rockhampton district. ${ }^{32}$ Even where the vice was not opium, an Asiatic source was often attributed. Baldwin Spencer wrote in Darwin in 1912; "The chinese are a great curse here. They get hold of the natives and give them opium and sundry vile concoctions that they call whiskey". ${ }^{33}$ These led to the "wholesale prostitution of native women". 34 "Nothing", he wrote, "is more patent than the rapid degeneration of the native in contact with the chinese". 35 His colleague, Frank Gillen, made the remarkable statement that "syphilis alone is responsible for the decay of the Australian aborigines"; adding that syphilis had been introduced by "Malay traders". ${ }^{36}$ It seems that while evolutionary theory explained extinction, death was better put down to Chinamen.

Despite the paucity of empirical data and the perfunctory treatment of the physical process, the doomed race idea was enormously influential in the late nineteenth and early twentieth centuries. European attitudes and actions toward Aborigines, including legislation, administration, employment, even to some extent missionary efforts, can be understood only in the context of a firm conviction that they had not long to live. The strength of this conviction derived from its foundations in a universal scientific law which could comprehend a diversity of observations about the Aborigines and about humanity in general. Moreover, the law of evolution dovetailed neatly with contemporary preoccupations and presuppositions about the nature of civilisation and man. This fit between scientific law and wider social concerns is worthy of further consideration

As the previous discussion of late nineteenth and early twentieth century anthropology indicates, human evolution was conceived as a single developmental sequence on which the various races of humankind represented different stages of advancement. This cast human evolution in a shape radically different to that suggested in The Origin of Species. Darwin depicted biological evolution as a growing tree of life, constantly putting forth new shoots and branches. Although some shoots soon withered and some branches dropped off, the tree of life was forever ramifying. Biological evolution was a process of diversification. Human evolution was more a process of convergence. No new shoots on the human tree developed into viable branches. The old branches merely dropped off, leaving nothing but a single stem striving ever upward. ${ }^{36}$ Of course, evolutionary scientists had to concede that at some point in the long distant past the races of mankind had diversified from a common human or anthropoid ancestor, but ever since that longago point of raciation there had been nothing but parallel development toward the same end, with some races surging ahead, others left behind and doomed to perish. ${ }^{37}$

This conception of the evolutionary process imbued it with direction and purpose, the ultimate end of which may not have been known, but its general tendencies were clearly apparent in the highest achievements of Western civilisation. The law of evolution was conflated with the idea of progress. Indeed, in much of the scientific literature the terms "evolution" and "progress" were interchangeable. Howitt's colleague, Lorimer Fison, was quite explicit in imputing a purpose and direction to evolution. He referred to it as "a 
steady progress toward the individualizing of the individual". Following the evolutionary process, he wrote:

at length we come to the civilised man with his personal rights and possessions and his gospel of political economy teaching him that self-seeking on the part of the individual must result in the greater good of the greater number. ${ }^{38}$

Statements explicitly equating evolution with progress were by no means uncommon in the scientific literature. Dr John Wild informed the first meeting of the Australasian Association for the Advancement of Science that anthropology provided:

evidence of a steady advance commencing with the first dawn of human life upon this globe, and that in spite of the numerous and terrible catastrophes which have overwhelmed one period of civilization after another, the higher type of man, like the phoenix of the fable, has always sprung up again from its ashes in order to continue its course toward a still higher destiny. ${ }^{39}$

The imputation of an ultimate purpose to the evolutionary process reached its most extreme form in the writings of the eugenists. The prominent British biometrician and eugenist, Karl Pearson, asserted that:

The [racial] struggle means suffering, intense suffering, while it is in progress; but that struggle and that suffering have been the stages by which the white man has reached his present stage of development, and they account for the fact that he no longer lives in caves and feeds on roots and nuts. This dependence of progress on the survival of the fitter race, terribly black as it may seem to some of you, gives the struggle for existence its redeeming features; it is the fiery crucible out of which comes the finer metal. 40

As an example of the "masterful human progress following an inter-racial struggle", Pearson cited the case of Australia, where a "lower race" had given way to "a great civilisation" 41

Not all scientists were prepared to endorse the extremes to which Pearson took the notion of struggle for survival in human societies. But all were agreed that without the stimulus of conflict and struggle a race would stagnate, as the Aborigines had in this quiet corner of the world. All agreed too, that the struggle for survival, which necessitated the elimination of the "unfit" and "inferior" specimens of humanity, ultimately tended toward the improvement and uplift of the species. Struggle for survival was the necessary means by which the path of human progress was swept clean of all inferior and primitive forms.

The imputation of direction and purpose to the course of human evolution sat oddly with Darwin's denial of just these attributes in the process of biological evolution and his emphasis on the selection of randomly occurring variations in populations. Alfred Russell Wallace, co-founder of evolutionary theory, had advised Darwin against the use of the term "natural selection" for its supposed implication of an agency determining the course of nature. ${ }^{42}$ Perhaps the notion that evolution, in human affairs, served some ultimate design would inevitably have been introduced, to fulfil a human need for order and meaning. In any case, Wallace's alternative term, "survival of the fittest" was no less fraught with dangerous implications. "Fittest", applied to human affairs was simply equated with conventional notions of good and desirable, and with the European's predetermined place at the pinnacle of the human hierarchy. Moreover, struggle for survival and survival of the fittest were concepts used in the pre-Darwinian period to explain not transmutation of species, but the means by which a species was kept true to its "type" while constantly striving upward toward its ideal form..$^{43}$ It was in this older sense of the term that the Social Darwinists, and the majority of Darwinian social scientists, applied the concept of survival of the fittest. Evolution was conceived as the means by which the racial "type" was constantly improved. 
The equation of evolution with progress was certainly not a mere incidental appendage; nor was it an importation into or a corruption of Darwin's own work. In a very literal sense, human evolution meant progress, and this meaning is apparent in Darwin's Descent of Man. ${ }^{44}$ Indeed, it is difficult to see how Darwin could have avoided the easy equation of evolution with progress, considering the shape in which his argument was cast. For one thing, he had to argue against the alternative degenerationist explanation of human variation; and he did this by simply inverting it, placing civilisation at the end rather than at the beginning of human enterprise. ${ }^{45}$ The option of explaining human variation in terms of divergent evolutionary paths was not available, for the existence of an evolutionary path was precisely what had to be proved.

More importantly, Darwin was faced with the problem of linking man to the primate forms from which he was supposed to have evolved without any generally accepted fossil evidence to fill the obvious gap. The notion of a racial hierarchy, borrowed from established racial science, went part of the way toward bridging this gap. ${ }^{46}$ This hierarchy, reinterpreted in temporal terms, automatically cast evolution in the shape of progress. Darwin admitted that the gap between even the lowest of savages and the highest of apes was still wide; but such breaks "between man and his nearest allies" were, he argued, the result merely of "the number of related forms which have become extinct". ${ }^{47}$ Moreover, he predicted that the gap would become wider still, for:

At some future period, not very distant as measured by centuries, the civilised races of man will almost certainly exterminate and replace throughout the world the savage races. At the same time the anthropomorphous apes ... will no doubt be exterminated. The break will than be rendered wider, for it will intervene between man in a more civilised state, as we may hope, than the Caucasian, and some ape as low as a baboon, instead of as at present between the negro or Australian and the gorilla. ${ }^{48}$

Conceived in these terms, racial extinction was a means of filling in the lacunae in the evolutionary argument. What better evidence could be offered for the reality of evolution/progress than the fact that redundant organisms were superseded by superior ones?

It is far too simplistic to regard the doomed race as an idea deriving its strength merely from its potential as a sop for disturbed consciences. It may well have fulfilled this function in certain contexts. Yet it is at least equally significant that the doomed race concept dovetailed neatly into overarching social and scientific presuppositions of the late nineteenth and early twentieth centuries. Aboriginal extinction followed logically from the assumption of their primitivity. It followed inevitably from the equation of evolution with progress. The messy details of population numbers and causes of death were quite peripheral. Aborigines had to become extinct, for humankind had to progress. Evolutionary theory, in its late nineteenth century form, not only made the world intelligible; it made nature meaningful. 


\section{NOTES}

1 This is a revised version of a paper originally presented at the AHA Conference at the University of Queensland on 29 September 1990. I wish to thank Henry Reynolds, Tracey McAskill and Gary Highland for their helpful comments.

2 J. Barnard, "Aborigines of Tasmania", Australasian Association for the Advancement of Science (hereafter AAAS) 2 (1890), p. 597.

3 See H. Reynolds, Frontier: Aborigines, Settlers and Land (Sydney: Allen \& Unwin, 1987), pp. 121-2.

4 William Dampier's opinion that the Aborigines were "the miserablest People in the world" is well known. See the extract from Dampier's A New Voyage Round the World in H. Reynolds, ed., Dispossession (Sydney: Allen \& Unwin, 1989), p. 97.

5 See N. Stepan, The Idea of Race in Science: Great Britain 1800-1960 (London: Macmillan, 1982), pp. 1-46; P. Jones, "Ideas linking Aborigines and Fuegians: from Cook to the Kulturkreis School", Australian Aboriginal Studies 2 (1989), pp. 2-13.

6 W. R. Smith, "Australian Conditions and Problems From the Standpoint of Present Anthropological Knowledge", AAAS 14 (1913), p. 374.

7 W. B. Spencer and F. J. Gillen, The Arunta, vol. 1 (London: Macmillan, 1927), p. vii.

8 A. W. Howitt, "Anthropology in Australia", Proceedings of the Royal Society of Victoria 3 (1891), p. 18.

9 See ibid., pp. 14-22, for a succinct statement of Howitt's views on social evolution. For a more comprehensive account, see A. W. Howitt, The Native Tribes of South East Australia (London: Macmillan, 1904); L. Fison and A. W. Howitt, Kamilaroi and Kurnai (Melbourne: George Robertson, 1880).

10 See, for example, W. B. Spencer, "Toternism in Australia", AAAS 10 (1904), pp. 376-423. See also the detailed biography of Spencer: D. J. Mulvaney and J. H. Calaby, "So Much that is New" : Baldwin Spencer, 1860-1929 (Carlton: Melbourne University Press, 1985).

11 See G. W. Stocking, Race, Culture, and Evolution: Essays in the History of Anthropology (New York: The Free Press, 1968), pp. 110-32.

12 T. H. Huxley, Man's Place in Nature (University of Michigan Press, 1959), pp. 178-80.

13 Science of Man 2, 2 (21 March 1899), p. 26.

14 See, for example, C. S. Wake, "The Mental Characteristics of Primitive Man, as Exemplified by the Australian Aborigines", Journal of the Anthropological Institute 1 (1872), p. 82. For an extended discussion of recapitulation theory see S. J. Gould, Ontogeny and Phylogeny (Cambridge, Mass.: Belknap Press, 1977).

15 W. L. Cleland, "President's Address", Transactions and Proceedings and Report of the Royal Society of South Australia 22 (1897-98), pp. 246-7.

16 W. R. Smith, "The Place of the Australian Aboriginal in Recent Anthropological Research", AAAS 11 (1907), p. 558.

17 Ibid., pp. 558-76; W. R. Smith, "Notes on Aboriginals of the Northem Territory of South Australia", Proceedings of the Royal Society of Edinburgh 27 (1907), pp. 56-9.

18 Science of Man 1, 4 (21 May 1898), p. 78.

19 Ibid. See also H. Klaatsch, The Evolution and Progress of Mankind (London: T. Fisher Unwin, 1923), pp. 99-102.

20 O. Schoetensack, "The Importance of Australia for the Evolution of Man from an Inferior Type", Science of Man 4, 12 (22 January 1902), p. 206.

21 Smith, "The Place of the Australian Aboriginal", p. 574.

22 W. L. Cleland, "President's Address", Transactions and Proceedings and Report of the Royal Society of South Australia 23 (1898-99), p. 307.

23 See L. R. Smith, The Aboriginal Population of Australia (Canberra: Australian National University Press, 1980), especially pp. 1-54.

24 Ibid., p. 131.

25 W. B. Spencer, "Preliminary Report on the Aboriginals of the Northem Territory", Commonwealth Parliamentary Papers, vol. III (1913), p. 41. 
26 The fate of the Tasmanians was freely cited as an example of racial extinction. It was acknowledged, however, that people of mixed Tasmanian-European descent still lived on the Bass Strait islands. This raises the question of what was meant by "racial extinction". Was it only "full-bloods" who would die out? Or were their "mixed-blood" descendants also doomed? The issues raised by these questions are too tangled to be entered into here.

27 C. Darwin, The Descent of Man, and Selection in Relation to Sex (London: John Murray, 1871), pp. 236-40.

28 See for example Fison and Howitt, Kamilaroi and Kurnai, p. 185.

29 Howitt, Native Tribes, p. xiii.

30 H. Klaatsch, "Some Notes on Scientific Travel Amongst the Black Population of Tropical Australia in 1904, 1905, 1906", AAAS 11 (1907), p. 578. See also H. Klaatsch, "Australian Aborigines", Proceedings of the Royal Society of Tasmania (1906-1907), p. xxvi.

31 C. Lumholtz, Among Cannibals (London: John Murray, 1889), pp. 363-4.

32 Joumal of first months of Spencer's residence in the Northem Territory during 1912, entry dated 30. 1. 1912. Australian Institute of Aboriginal and Torres Strait Islander Studies, W. B. Spencer Papers, MS 71, Box 1, item 5. AIATSIS MS 71 are photocopies of original documents held by the Pitt-Rivers Museum, Oxford.

33 Spencer, "Preliminary Report", p. 42.

34 Ibid., p. 43.

35 South Australia, Legislative Council Select Committee on the Aborigines Bill, 1899, Minutes of Evidence, p. 99.

36 J. A. Barnes pointed out the inapplicability of Darwin's tree analogy to the scheme of human evolution advanced by late nineteenth and early twentieth century anthropologists. See J. A. Bames, "Anthropology in Britain Before and after Darwin", Mankind 5, 9 (July 1960), p. 384.

37 See, for example, A. R. Wallace, "The Origin of Human Races and the Antiquity of Man Deduced from the Theory of Natural Selection"', Journal of the Anthropological Society of London II (1864), pp. clviii-clxxxvii.

38 Fison and Howitt, Kamilaroi and Kurnai, p. 128. Italies in the original.

39 J. Wild, "Outlines of Anthropology", AAAS 1 (1888), p. 446.

40 K. Pearson, National Life from the Standpoint of Science (London: Adam and Charles Black, 1901), p. 24.

41 Ibid., p. 23.

42 G. Jones, Social Darwinism and English Thought: The Interaction Between Biological and Social Theory (Brighton, Sussex: Harvester Press, 1980), pp. 31, 143.

43 Ibid., pp. 5-6.

44 Darwin, Descent, especially pp. 93-106, 180-4.

45 Ibid., especially pp. 180-4.

46 Stocking, Race, Culture, and Evolution, p. 113; Stepan, Race in Science, pp. 53-5.

47 Darwin, Descent, pp .200-1. 